\title{
UTILIZAÇÃO DO MAPA DE USO DO SOLO NA IDENTIFICAÇÃO DE ÁREAS POTENCIAIS DE SOLO DEGRADADO
}

\author{
Diego Herzog de Carvalho ${ }^{(a)}$, Aline Carneiro Silverol ${ }^{(b)}$ \\ (a) Graduando em Geografia / Departamento de Geografia / Universidade Federal do Espírito Santo, E-mail: \\ diegoherzogcarvalho@gmail.com; \\ (b) Bolsista Pós-Doc / Departamento de Geografia / Universidade Federal do Espírito Santo, E-mail: \\ aline.silverol@pq.cnpq.br
}

\section{Eixo: SOLOS E PAISAGEM.}

\section{RESUMO}

A identificação e a caracterização de áreas sob processos de degradação do solo provocados por atividades antrópicas extensivas e/ou familiares é de grande importância para o planejamento correto de ações de prevenção, planejamento e remediação desses processos. O objetivo deste trabalho é apresentar os resultados obtidos com a utilização do software ArcGIS 10.1, associado ao método de classificação não supervisionada, com base em dados fornecidos por órgãos públicos, na identificação de áreas degradadas e áreas com potencial de degradação no município de Serra ES. O mapa obtido e as interpretações realizadas permitiram identificar $175,38 \mathrm{~km}^{2}$ de áreas potenciais em degradação presente, em grande parte na zona rural do município, associado aos processos históricos de esvaziamento do campo ocorrido no estado, o que demonstra a eficiência da utilização de geotecnologias no monitoramento e identificação das áreas com diferentes condições ambientais.

Palavras chave: Poluição e degradação dos solos. uso do solo. agropecuária, mapeamento. ArcGIS

\section{Introdução}

Segundo a EMBRAPA (2006) o solo é uma coleção de corpos naturais, "constituído por partes sólidas, líquidas e gasosas, tridimensionais, dinâmicos, formados por materiais minerais e orgânicos que ocupa a maior parte das extensões continentais do planeta. Esses materiais minerais e orgânicos organizados de forma específica no solo possibilitam, dentre outras atividades, o cultivo de plantas na agricultura e a criação de animais na pecuária, em atividades extensivas ou familiares.

No caso do Brasil, ambas as atividades possuem grande representatividade econômica e refletem também nos mercados internacionais, alcançando patamares importantes em rankings internacionais de produção primária.

No entanto, o forte cultivo extensivo no país, que segundo censo do IBGE de 2006 (censo agropecuário) chegou a 329.941.393 hectares cultivados, tem causado danos irreversíveis, em alguns casos, ao solo, como a empobrecimento e exposição do mesmo após desmatamento. 
Estudos como o de Silva Filho (2002) sobre a degradação de solos em áreas de pastagem no município de Porto Velho - RO indicaram que, após a retirada da cobertura vegetal do solo, toda a atividade macro e microbiológica é alterada de forma temporária e/ou permanente, causando danos às estruturas tanto físicas quanto químicas de estabilidade do solo.

Ainda segundo Silva Filho (2002), o solo que também é exposto ao manejo pecuário durante determinados períodos excedentes provoca a degradação dos solos em vários níveis, prejudicando a capacidade de resiliência desse solo, que, por consequência, extingue a quantidade de nutrientes disponíveis.

Conceitualmente, a poluição dos solos pode ser entendida, segundo Decreto n. 28.687/82, art. 72, como a “deposição, disposição, descarga, infiltração, acumulação, injeção ou enterramento no solo, ou no subsolo de substâncias ou produtos poluentes, em estado sólido, líquido ou gasoso".

No Espírito Santo os solos em algum estágio potencial de degradação estão em sua maioria presentes em áreas agrícolas (principalmente do cultivo de café) e de pastagens na região Noroeste do estado, "devido à fragilidade dos solos, elevada erosividade das chuvas e a pouca cobertura vegetal nas áreas durante o ano" (CORREIA, 2011).

O planejamento e o monitoramento por meio da utilização de geotecnologias têm contribuído de forma efetiva na identificação dos diferentes usos atribuídos ao solo. Pepe, Campos e Alovisi Júnior (2009) mapearam a região urbana do município de Dourados, MS, a fim de identificar fundos de vale carecidos de conservação ambiental, utilizando imagens do satélite CEBERS - 2B e o software SPRING 4.3.3 para tratamento das imagens posteriormente.

O mapa de uso do solo também possibilitou Lopes (2008) mapear as áreas antropizadas em 224377,483ha ocasionado por exploração ilegal de madeira, queimadas, derrubada da floresta para a prática agropecuária e pastagens no município de Tailândia - PA.

Portanto, observando a necessidade de identificação de áreas em degradação potencial através de shapes de uso do solo fornecidos pelo Instituto Jones dos Santos Neves - IJSN/ES e pelo software ArcGIS 10.1, este trabalho elaborou um mapa de uso do solo identificando como potencial as áreas de pastagem e solo exposto no município da Serra - ES. 


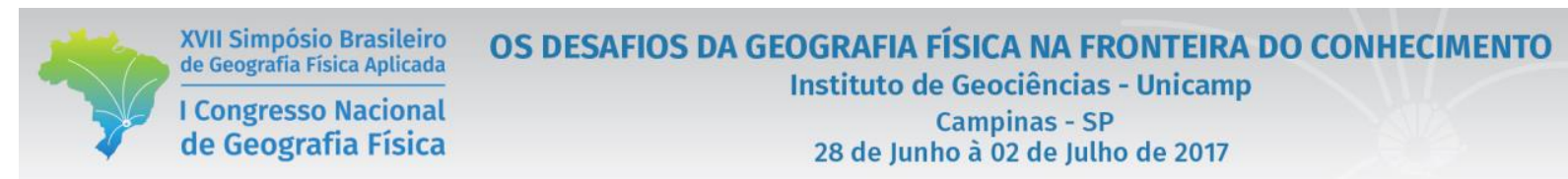

\section{Materiais e Métodos}

\section{1 Área de Estudo}

O município da Serra está localizado no litoral do Espírito Santo, ao Norte da capital Vitória, e faz fronteira, ao norte, com o município de Fundão, a Oeste com o Município de Santa Leopoldina e a Sudoeste com Cariacica.

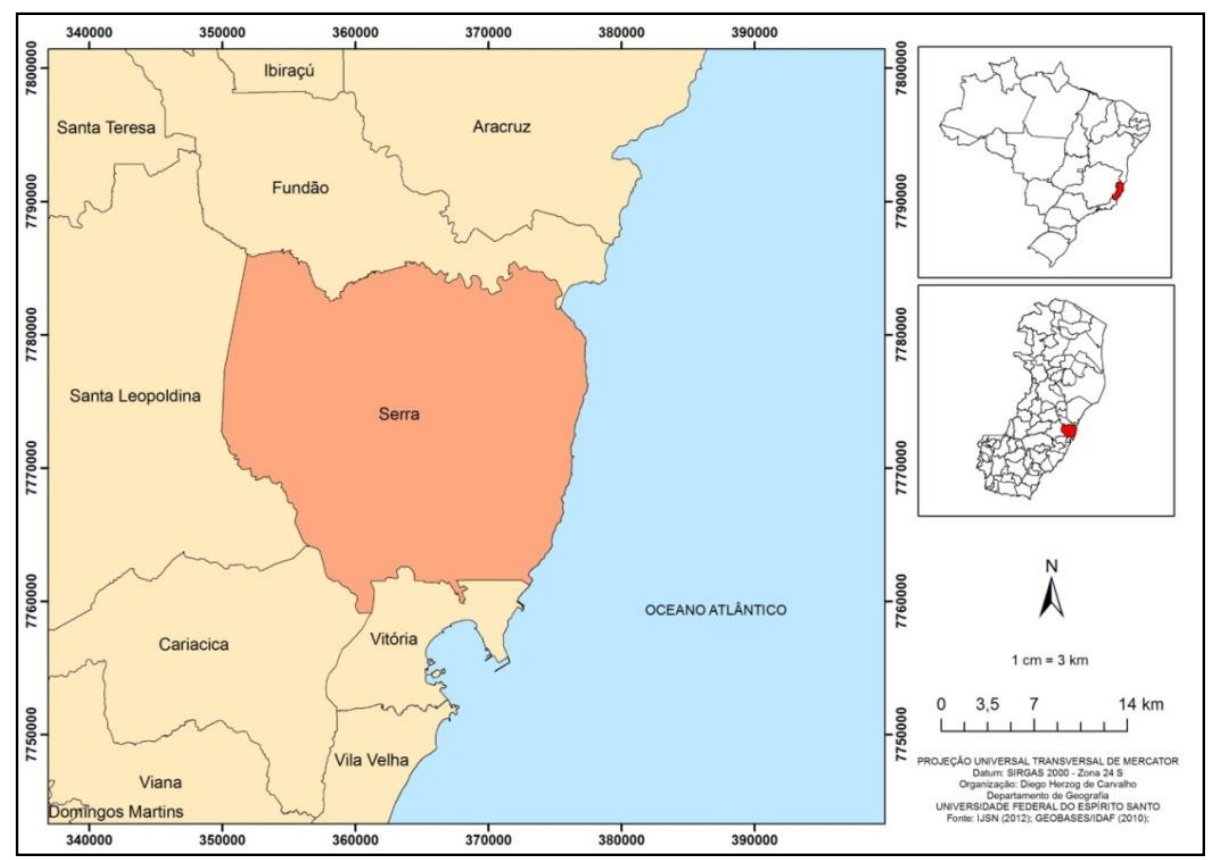

Figura 1 - Mapa de identificação da área de estudo.

A fisionomia do relevo é bastante acidentada com variações entre colinas e planaltos e um maciço central, Mestre Álvaro, "com amplitude topográfica superior a 800 metros - localizada no município" (BRICALLI, 2015).

\subsection{Metodologia}

Foram consultadas referências relacionadas ao tema, e alguns dados disponibilizados na página da prefeitura da Serra, Governo do Estado do Espírito Santo, e do Instituto Brasileiro de Geografia e Estatística-IBGE e também do Instituto Jones dos Santos Neves-IJSN. Os shapes foram elaborados no Laboratório de Geotecnologias da UFES, a partir dos dados fornecidos pelo IJSN, utilizando método de classificação não supervisionada, e posterior correção dos polígonos e elaboração dos mapas em software ArcGIS 10.1. 


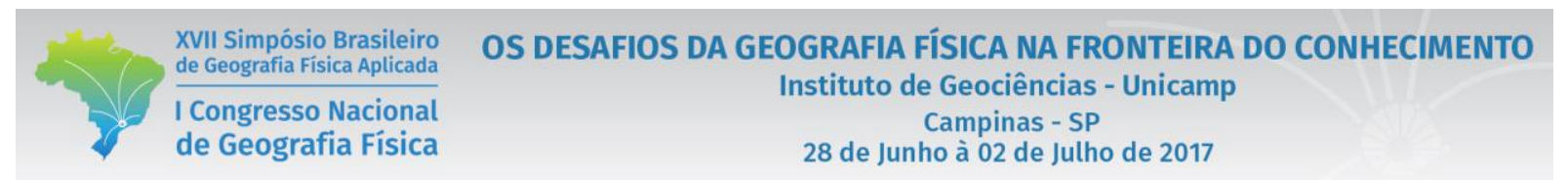

\section{Resultados e Discussão}

\subsection{Mapa de Uso do solo}

A classificação supervisionada é comumente utilizada na caracterização de mapas de uso do solo, para identificação e correlação de áreas com atividade semelhante, como cultivo de alimentos, pastagens, zona urbana, entre outros.

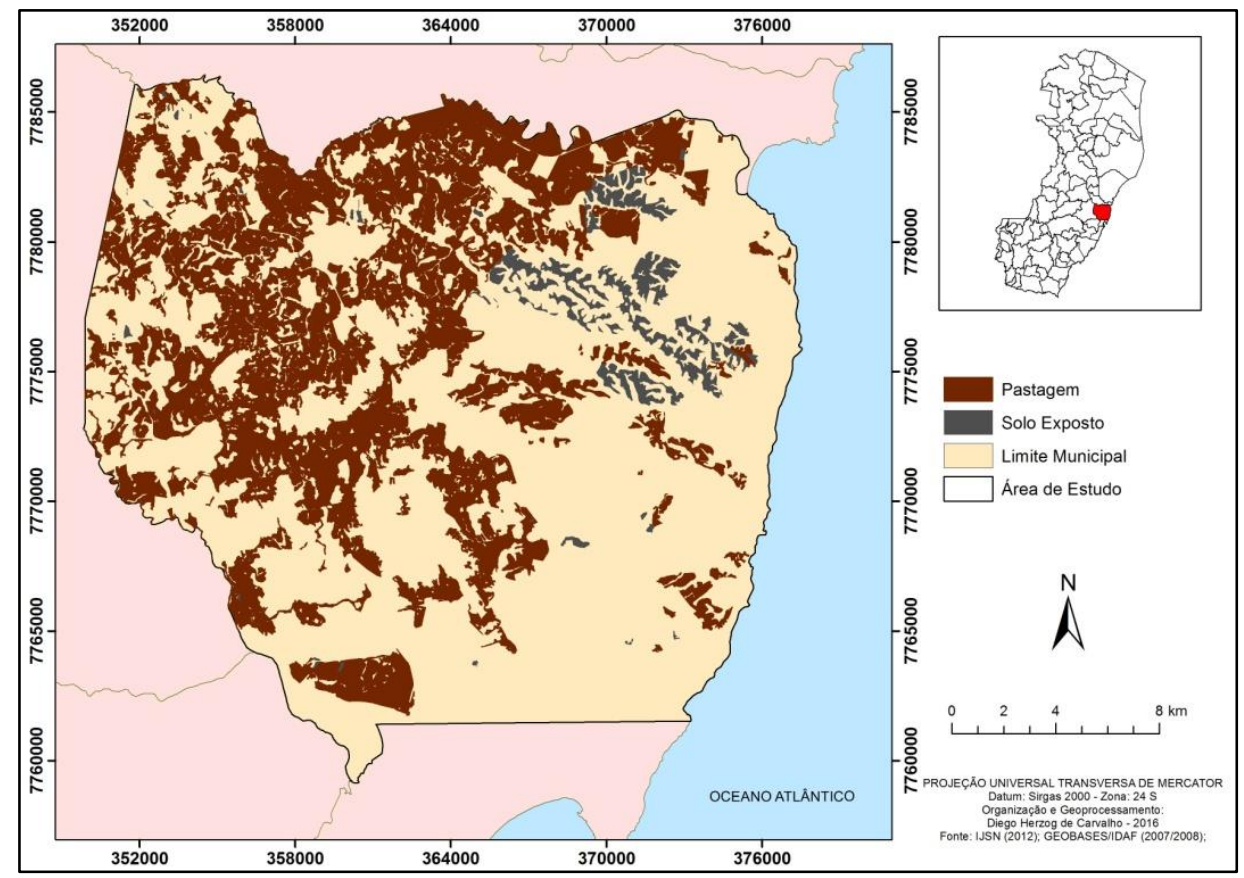

Figura 2 - Mapa municipal da Serra elaborado com shape de 'uso do solo', destacando as categorias de pastagem e solo exposto analisadas.

A figura 2 apresenta as áreas que compreendem as atividades de pastagem e solo exposto potenciais na degradação do solo. A falta da vegetação de grande porte, característico de uma área preservada em mata atlântica, é bastante evidente nos pontos delimitados com polígonos marroms. Além da presença de processos como ravinamento e vossorocamento nos locais de solo exposto (sem a presença de vegetação) delimitada com polígonos cinza.

\section{Considerações Finais}

Áreas de 'solo exposto' e de 'pastagem', assim como com outras atividades relacionadas ao uso do solo, podem se tornar de grande potencial degradador sem um manejo adequado durante, ou posteriormente, a atividade. Com a ajuda software ArcGIS 10.1, na elaboração do mapa de uso de solos no município da Serra, tornou-se possível identificar as áreas de maior potencial. A área delimitada por polígonos abrange 


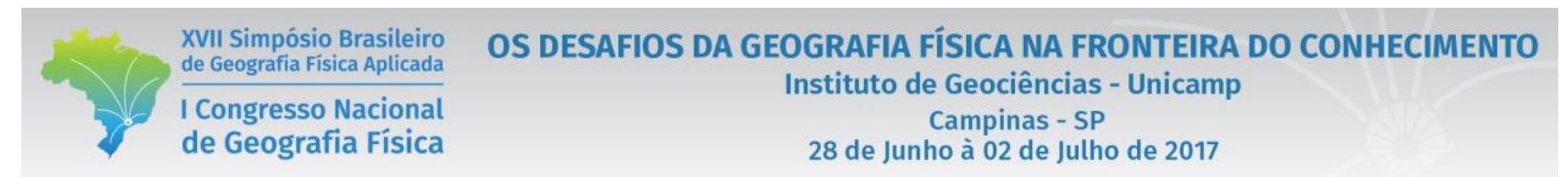

175,38 km² do território no município, e está presente, em sua maior porção, na zona rural, tendendo a associação a áreas de pastagem inutilizadas. Acredita-se que o uso de geotecnologias em conjunto com a pesquisa em campo e em laboratório tendem a enriquecer ainda mais o diagnóstico da potencial degradação de regiões com solo degradado.

\section{Referências}

BRICALLI, Luiza Leonardi; QUEIROZ NETO, José Pereira de. CARACTERIZAÇÃO MORFOLÓGICA E PEDOLÓGICA DE UMA DEPRESSÃO (SERRA-ES-BRASIL). Sociedade \& Natureza, [s.1.], v. 27, n. 2, p.309325, ago. 2015. FapUNIFESP (SciELO). <http://dx.doi.org/10.1590/1982-451320150209>.

CENSO AGROPECUÁRIO 2006. Instituto Brasileiro De Geografia e Estatística - IBGE. Ministério do Desenvolvimento Agrário e Ministério do Planejamento, Orçamento e Gestão, 2006.

CORREIA, Francisley Lucas. Produto C: Relatório Com Diagnóstico Descritivo das Condições Atuais das Áreas Suscetíveis a Desertificação do Estado do Espírito Santo sob a Ótica do Eixo Temático do PAN-Brasil "Ampliação Sustentável da Capacidade Produtiva", a Partir da Análise de Dados Secundários Existentes, Buscando Inclusive a Atualização do Panorama de Desertificação no Estado do Espírito Santo. Vitória: Instituto Interamericano de Cooperação Para Agricultura - Inca, 2011. 57 p. (PCT BRA/IICA/05/004). Disponível em: <http://www.iicabr.iica.org.br/wp-content/uploads/2014/03/Produto-C-Francisley-Correia-PAE-ES.pdf >. Acesso em: 15 jan. 2017.

EMPRESA BRASILEIRA DE PESQUISA AGROPECUÁRIA - EMBRAPA. Centro Nacional de Pesquisa de Solos. Sistema brasileiro de classificação de solos. Rio de Janeiro, 2006. 306p.

LOPES, Luís Henrique Moreira. Uso e Cobertura do Solo no Município de Tailândia-Pa Utilizando o Tm/Landsat e Técnica de Classificação Não-Supervisionada. Engevista, Rio de Janeiro, v. 10, n. 2, p.126-132, dez. 2008. Disponível em: 〈http://www.uff.br/engevista/2_10Engevista5.pdf〉. Acesso em: 01 fev. 2017.

PEPE, Thiago Augusto de Paula; CAMPOS, Bruno Ferreira; ALOVISI JÚNIOR, Valmor. O uso de geotecnologias na identificação e delimitação de áreas prioritárias para conservação na cidade de Dourados, MS. In: SIMPÓSIO DE GEOTECNOLOGIAS NO PANTANAL, 2., 2009, Corumbá. Anais. Corumbá: Embrapa Informática Agropecuária/inpe, 2009. p. 567 - 576.

SILVA FILHO, E.P.; CARNEIRO, E.X.P E CARNEIRO, C. Avaliação da compactação de solos em áreas de pastagem no Muncípio de Porto Velho - RO- Amazônia ocidental. Primeira Versão, ano II, $\mathrm{n}^{\circ}$ 108, agosto de 2002. ed. Edufro. 2002. 